\title{
Influência da adubação verde e diferentes adubos orgânicos na produção de fitomassa aérea de atroveran (Ocimum selloi Benth.)
}

\author{
MORAIS, L.A.S.*; BARBOSA, A.G. \\ Laboratório de Produtos Naturais, Embrapa Meio Ambiente, Caixa Postal 69, CEP: 13820-000, Jaguariúna-Brasil \\ *ilia@cnpma.embrapa.br
}

\begin{abstract}
RESUMO: Este trabalho teve por objetivo verificar o efeito de diferentes adubos orgânicos em associação ou não com adubo verde na produção de folhas de Ocimum selloi Benth., planta nativa do Brasil. O experimento foi conduzido na área experimental da Embrapa Meio Ambiente (CNPMA), localizado no município de Jaguariúna, em duas áreas distintas, sendo uma delas submetidas anteriormente ao plantio e incorporação de adubo verde (Crotalaria juncea). Os tratamentos utilizados foram T1 - testemunha (solo sem adubação), T2 - cama de aviário $\left(5 \mathrm{~kg} \mathrm{~m}^{-2}\right)$, T3 - hidrolisado de peixe (produto comercial Fishfértil - $5 \mathrm{~mL} \mathrm{~m}^{-2}$ ) e T4 - composto orgânico (4 kg $\mathrm{m}^{-2}$ ). A colheita foi realizada 180 dias após o plantio, em janeiro de 2011 , sendo colhidas as plantas úteis (quatro plantas por parcela). Avaliou-se o rendimento de fitomassa fresca e seca. $O$ delineamento experimental adotado foi o esquema fatorial $2 \times 4$, com quatro repetições (blocos). As médias obtidas foram submetidas à análise de variância seguida de teste de médias (Tukey). Com base nos resultados obtidos, pode-se concluir que a cama de aviário apresentou resultados mais satisfatórios quanto à produção de folhas de Ocimum selloi quando comparados aos demais tratamentos orgânicos, não se observando incremento nos resultados pela associação com o adubo verde Crotalaria juncea.
\end{abstract}

Palavras-chave: Ocimum selloi, Crotalaria juncea, cama-de-aviário, hidrolisado de peixe

\begin{abstract}
Influence of green manure and different organic manure on production of aereal phytomass of Ocimum selloi. The aim of this work was to avail the effect of different manures in association or nor with green manure on yield of leaves of Ocimum selloi Benth. The assay was accomplished on experimental area of Embrapa Environmental (Jaguariúna district), at two different spaces (with or without green manure Crotalaria juncea). The treatments used were T1 - witness (no manure), T2 - chicken manure $\left(5 \mathrm{~kg} \mathrm{~m}^{-2}\right), \mathrm{T} 3$ - commercial product Fishfértil $\left.5 \mathrm{~mL} \mathrm{~m}^{-2}\right)$ and T4 - composting $\left(4 \mathrm{~kg} \mathrm{~m}^{-2}\right)$. The cut was realized on 180 days after the planting (january - 2011), and were collected four plants/ plot. The yield of dried and fresh Ocimum selloi phytomass was availed. The experimental design was factorial scheme (2x4), with four repetitions. The treatment with chicken manure showed best results on Ocimum selloi leaves yield than the others treatments, but did not was influence by using Crotalaria juncea.
\end{abstract}

Key words: Ocimum selloi, Crotalaria juncea, Fishfértil; chicken manure

\section{INTRODUÇÃO}

Entre as plantas nativas de uso medicinal do Brasil, encontra-se o Ocimum selloi Benth., planta da família Lamiaceae que ocorre nas regiões Sudeste e Sul (Schmidt, 1858), utilizada como antidiarréico, antiespasmódico e antiinflamatório, propriedades comprovadas por testes pré-clínicos por Vanderlinde et al. (1994), vulgarmente conhecida como elixir paregórico, alfavaquinha ou atroveran. Estes termos populares se referem às suas propriedades farmacológicas (por ter uso semelhante ao medicamento comercialmente conhecido como elixir paregórico), químicas (anis, pela semelhança de odor com os aquênios de Pimpinella anisum ou Foeniculum vulgare, erva doce e funcho, respectivamente) e à semelhança com outras espécies do gênero Ocimum (Martins, 1998). Atribui-se ao estragol (ou metilchavicol), um componente do óleo essencial, o aroma anisado desta espécie, sendo utilizado como

Recebido para publicação: setembro de 2011

Aceito para publicação: março de 2012

Rev. Bras. PI. Med., Botucatu, v.14, n.esp., p.246-249, 2012. 
flavorizante em alimentos e licores e na formulação de perfumes (Windholz, 1976).

Em estudos sobre a composição química do óleo essencial de folhas de duas amostras de Ocimum selloi, sendo a primeira proveniente de população espontânea, coletada no Paraná e a segunda, proveniente da mesma população, porém, cultivada em Botucatu, Morais et al. (2002a) observaram a ausência de anetol em ambas as amostras. O óleo essencial da primeira amostra apresentou como substância majoritária, a elimicina (43,66\%), pertencente à classe dos fenilpropanóides, como o anetol, sendo esta a primeira citação da literatura referente à presença de elimicina no óleo essencial de Ocimum selloi.

Segundo Morhy (1973), Ocimum selloi Benth. é planta herbácea, perene, que atinge 1,20 $\mathrm{m}$ de altura, florescendo ao longo de todo o ano. Schmidt (1858), citado por Martins (1998), descreve O. selloi como uma planta anual herbácea, pertencente à família Lamiaceae, que ocorre nas regiões Sudeste e Sul do Brasil. O conflito de informações pode ser devido a diferenças no manejo, ou, por se tratar de variedades ou cultivares diferentes.

Segundo Bustamante (1993), o termo Ocimum é oriundo do grego "ókimom", que significa perfumado, devido ao cheiro exalado pelas folhas e inflorescências. O gênero Ocimum compreende cerca de 30 espécies (Paton et al., 1999), muitas das quais empregadas pela população como medicinais, na culinária e no controle de insetos. São espécies ricas em óleos essenciais. Ocimum basilicum, conhecida como manjericão, é a espécie mais popularmente utilizada, estimando-se uma produção mundial de 42,5 t ano $^{-1}$ (Grayer, 1996).

De acordo com Capellari Júnior (1995), o único tipo de adubação aceita no cultivo de plantas medicinais é a orgânica. A adubação orgânica tem sido recomendada para plantas medicinais como parte de uma série de praticas da agricultura orgânica nas diversas correntes, que são sintetizadas nas normas técnicas da "Associação de Agricultura Orgânica” (AAO), sendo recomendados de 3 a $5 \mathrm{~kg}$ $\mathrm{m}^{-2}$ de composto orgânico ou esterco de curral curtido. Deve-se evitar o uso de compostos a base de lixo urbano, pois estes podem conter resíduos de metais pesados, o que afetaria a qualidade final das plantas (Martins et al., 1995).

Segundo Box (1973), as plantas medicinais oriundas de cultivo orgânico são mais resistentes a pragas e doenças, reduzindo-se a necessidade de controle fitossanitário. A utilização de agrotóxicos em plantas medicinais pode causar interferência na composição das substancias ativas, chegando, em algumas situações, a inviabilizar o uso da planta para fins medicinais.

A prática da adubação orgânica, além de fornecer nutrientes às plantas, proporciona melhoria da estrutura física do solo, aumenta a retenção de água, diminui as perdas por erosão, favorece o controle biológico devido à maior população microbiana e melhora a capacidade tampão do solo (Lopes, 1989). O adubo orgânico também aumenta a capacidade de troca catiônica, eleva o pH, reduzindo o teor de alumínio trocável (Primavesi, 1982).

A adubação verde é uma técnica milenar, em que plantas leguminosas são as mais utilizadas devido ao grande potencial em fixar nitrogênio atmosférico, via simbiose com rizóbios. Consiste no cultivo de plantas para serem mantidas em cobertura ou incorporadas ao solo com a finalidade de preservar a fertilidade das terras (Calegari et al., 1993). O plantio de leguminosas contribui para diminuir a população das plantas espontâneas, além de ser fonte de matéria orgânica para o solo. Segundo Gonzáles (1980), esta prática propicia a formação de ácidos orgânicos que aumentam a solubilização de minerais e intermediam o bombeamento de nutrientes de camadas mais profundas do solo, disponibilizandoos para plantas com sistema radicular superficial.

De acordo com Espíndola et al. (1997) e Barradas (2010), os benefícios da prática da adubação verde relacionam-se diretamente com o ganho de matéria orgânica no sistema, proporcionando melhoria das propriedades físicas, químicas e biológicas do solo. A prática da adubação verde pode acarretar em um importante aporte de matéria orgânica, nitrogênio e outros nutrientes ao sistema, o que pode tornar o produtor menos dependente de estercos e compostos.

Diante do exposto, este trabalho teve por objetivo verificar o efeito de diferentes adubos orgânicos em associação ou não com adubo verde na produção de folhas de Ocimum selloi.

\section{MATERIAL E MÉTODO}

O experimento foi conduzido na área experimental da Embrapa Meio Ambiente (CNPMA), localizada no município de Jaguariúna, Estado de São Paulo. Para a instalação da cultura no campo, foram realizadas a análises químicas do solo (0-20 e 20-40 centímetros de profundidade). A composição de macro e micronutrientes dos adubos e compostos utilizados também foi analisada. As mudas de Ocimum selloi foram produzidas sob cultivo protegido a partir de sementes, preparadas em bandejas 128 células. As mudas foram transplantadas para o campo 60 dias após a semeadura, para áreas vizinhas, porém distintas: a primeira área não recebeu plantio de adubo verde; a segunda foi cultivada com adubo verde (Crotalaria juncea), sendo este incorporado ao solo 60 dias antes do plantio das mudas de O. selloi no campo. Os tratamentos constaram de três tipos diferentes de adubos orgânicos; além de uma

Rev. Bras. PI. Med., Botucatu, v.14, n.esp., p.246-249, 2012. 
testemunha, totalizando quatro tratamentos e quatro repetições. Os tratamentos utilizados foram T1 testemunha (solo sem adubação), T2 - cama de aviário $\left(5 \mathrm{~kg} \mathrm{~m}^{-2}\right), \mathrm{T3}$ - hidrolisado de peixe (produto comercial Fishfértil Active, fertilizante orgânico oriundo de um processo natural de fermentação enzimática de pescados marinhos para aplicação no solo $-5 \mathrm{~mL} \mathrm{~m}^{-2}$, seguindo as especificações do fabricante) e T4 composto orgânico $\left(4 \mathrm{~kg} \mathrm{~m}^{-2}\right)$. A incorporação de todos os adubos orgânicos foi feita na área da parcela (por $\mathrm{m}^{2}$ ) quinze dias antes do transplante das mudas. A colheita foi realizada 180 dias após o plantio, em janeiro de 2011, sendo colhidas as plantas úteis (quatro plantas por parcela). Foi feita a separação das folhas em laboratório, observando-se o rendimento de massa fresca e seca (secagem em estufa de circulação de ar forçada, a $35^{\circ} \mathrm{C}$ por quatro dias). $\mathrm{O}$ delineamento experimental adotado foi o esquema fatorial $2 \times 4$, com quatro repetições (blocos). Utilizouse espaçamento de 0,4 m entre plantas e 0,6 $\mathrm{m}$ entre linhas. O espaçamento entre as parcelas foi de 0,8 $\mathrm{m}$; de $1,0 \mathrm{~m}$ entre os blocos. Foram plantadas 16 plantas por parcela, sendo quatro úteis, para se reduzir o efeito bordadura. Avaliou-se a produção de folhas. Os dados obtidos foram submetidos à análise de variância seguida de teste de médias (Tukey).

\section{RESULTADO E DISCUSSÃO}

Após a realização da análise estatística observou-se que interação não foi significativa. Os resultados obtidos não demonstraram diferença significativa no rendimento de folhas de $O$. selloi submetido ou não à adubação verde (Tabela 1), obtendo-se as média de 187,0 g por 4 plantas e 167,1 g por 4 plantas, respectivamente. Isto pode ter ocorrido pela ocorrência de mineralização, liberação rápida e posterior perda por lixiviação dos nutrientes, principalmente quando incorporados e de baixa relação C/N (Kiehl, 1985). Segundo Barradas (2010), é recomendável que o produtor tenha em mente que os melhoramentos no sistema de produção podem não vir de imediato, pois como se trata de sistema, é preciso que se dê tempo para que o processo possa dar resposta.

Com relação à produção de fitomassa seca (Tabela 2) da parte aérea (folha), houve diferença significativa entre os tratamentos, tendo o tratamento T2 (cama-de-aviário - $5 \mathrm{~kg} \mathrm{~m}^{-2}$ ), o maior rendimento 280,37 g por 4 plantas (Tabela 2). O tratamento T3

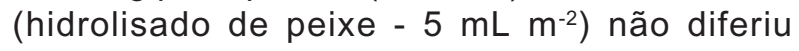
significativamente da testemunha e do composto orgânico, quanto à produção de folhas.

Resultados semelhantes foram observados por Morais et al. (2002b) em cultivo de O. selloi submetido à diferentes doses de adubo orgânico e mineral. Os tratamentos orgânicos (esterco de curral
TABELA 1. Média de produção (base seca) de folhas de Ocimum selloi, cultivado em área com e sem adubo verde. Jaguariúna-SP, 2011.

\begin{tabular}{lc}
\hline Tratamentos & $\begin{array}{c}\text { Produção de fitomassa (folhas) } \\
\text { Base seca (g/4 plantas) }\end{array}$ \\
\hline Com adubo verde & $186,97 \mathrm{~A}$ \\
Sem adubo verde & $167,08 \mathrm{~A}$ \\
\hline CV $(\%)$ & $20,70 \%$ \\
\hline
\end{tabular}

Médias seguidas da mesma letra na coluna, não diferem entre si pelo teste de Tukey a $1 \%$ de probabilidade.

TABELA 2. Média de produção (base seca) de folhas de Ocimum selloi, submetido a diferentes tipos de adubação. Jaguariúna-SP, 2011.

\begin{tabular}{lc}
\hline Tratamentos & \multicolumn{1}{c}{$\begin{array}{c}\text { Produção de fitomassa (folhas) } \\
\text { Base seca }(\mathrm{g} / 4 \text { plantas) }\end{array}$} \\
\hline T1 - Testemunha & $114,58 \mathrm{C}$ \\
T2 - Cama de aviário $\left(5 \mathrm{~kg} \mathrm{~m}^{-2}\right)$ & $280,37 \mathrm{~A}$ \\
T3 - Fishfértil $\left(5 \mathrm{~mL} \mathrm{~m}^{-2}\right)$ & $131,30 \mathrm{BC}$ \\
T4 - Composto orgânico $\left(4 \mathrm{~kg} \mathrm{~m}^{-2}\right)$ & $181,87 \mathrm{~B}$ \\
\hline $\mathrm{CV}(\%)$ & $20,70 \%$ \\
\hline
\end{tabular}

Médias seguidas da mesma letra na coluna, não diferem entre si pelo teste de Tukey a $1 \%$ de probabilidade.

curtido) apresentaram maior rendimento de caules, folhas e inflorescências quando comparados aos adubos minerais. Blank et al. (2005) observaram que cultivo de $O$. gratissimum submetido a esterco de galinha associado ou não com Hortosafra ${ }^{\circledR}$ apresentou produção de matéria seca da parte aérea significativamente superior aos tratamentos nos quais as plantas foram adubadas exclusivamente com esterco bovino.

Santos et al. (2009) realizaram experimentos com Melissa officinalis, sendo as plantas submetidas a diferentes doses de adubos orgânicos (esterco bovino e biofertilizante comercial), associados ou não, obtendo-se aumento expressivo no rendimento de folhas, nos tratamentos com esterco bovino.

Estudando o efeito da cama-de-aviário semidecomposta $\left(2 \mathrm{~kg} \mathrm{~m}^{-2}\right)$ sobre a produção de matérias frescas e secas de parte aérea de hortelã branca (Mentha cf. longifolia Huds.) e hortelã comum (Mentha $x$ villosa Huds.), Vieira et al. (2002) observaram que na espécie $M$. cf. longifolia houve o maior rendimento de fitomassa, sendo que a cama-de-aviário proporcionou aumento no rendimento de fitomassa em ambas as espécies, quando comparada à testemunha (sem adubação), apenas no primeiro corte. Chaves (2002) estudou o efeito de diferentes doses de adubo orgânico (cama-de-aviário) na produção de folhas, de caules, de inflorescências de O. gratissimum. O autor concluiu que doses crescentes de esterco de poedeira favoreceram um 
aumento na produção dos componentes da parte aérea da planta (folhas, caules e inflorescências).

Barboza et al. (2010) avaliaram a produção de Pfaffia glomerata (fáfia) em monocultivo e policultivos com Tagetes erecta (cravo-de-defunto) e Ocimum basilicum (manjericão), sem e com incorporação de cama-de-frango semi-decomposta. Os autores observaram que a produção de fitomassa fresca e seca da parte aérea da fáfia foi maior $(13,22$ t ha-1 e 4,39 t ha $^{-1}$, respectivamente) em monocultivo, independentemente do uso da cama-de-frango. As produções de massas frescas e secas dos capítulos florais do cravo-de-defunto foram maiores $\left(14,28 \mathrm{t} \mathrm{ha}^{-1}\right.$ e 1,278 t ha $^{-1}$, respectivamente) no policultivo com a fáfia, mas apenas a produção de massa fresca dos capítulos foi maior $\left(14,17 \mathrm{t} \mathrm{ha}^{-1}\right)$ com o uso da camade-frango. A produção de parte aérea do manjericão foram maiores $\left(52,91 \mathrm{t} \mathrm{ha}^{-1}\right)$ no policultivo, independentemente de qual espécie; porém, não foi influenciada pelo uso da cama-de-frango. A razão de área equivalente (RAE) para o policultivo da fáfia com o cravo-de-defunto foi de 2,15 com cama-de-frango e de 1,99 sem cama e com o manjericão, foi 2,44 com cama e de 3,08 sem cama.

Segundo Matos (1996), os adubos nitrogenados exercem importante papel no incremento do volume da colheita em plantas medicinais das quais se aproveitam as folhas e inflorescências e, as adubações fosfatada e potássica são particularmente importantes para as culturas cujos produtos são frutos secos, sementes e partes subterrâneas.

Com base nos resultados obtidos, pode-se concluir que a cama-de-aviário apresentou melhores resultados quanto à produção de folhas de Ocimum selloi quando comparada aos demais tratamentos orgânicos, não se observando incremento nos resultados pela associação com o adubo verde Crotalaria juncea.

\section{REFERÊNCIA}

BARBOZA, V.C. et al. Cama-de-frango em mono e policultivo de fáfia com cravo-de-defunto e manjericão. Horticultura Brasileira, v.28, p.348-54, 2010.

BARRADAS, C.A.A. Adubação verde. Niterói: Programa Rio Rural. 2010. 12p. (Manual Técnico; 25).

BLANK, A.F. et al. et al. Influência da adubação orgânica e mineral no cultivo de manjericão cv. Genovese. Revista Ciência Agronômica, v.36, p.175-80, 2005.

BOX, M.M. Cultivo de Plantas Medicinales. 2.ed., v.1, 1973. 418p.

CALEGARI, A. et al. Methods of soil analisys. 2.ed., Madison: American Society of Agronomy, 1980. p.595624. (Agronomy 9).

CHAVES, F.C.M. Produção de biomassa, rendimento e composição de óleo essencial de alfavaca-cravo (Ocimum gratissimum L.) em função de adubação orgânica e épocas de corte. 2002. 144p. Botucatu: FCAUNESP. 144 p. Tese (Doutorado em Produção Vegetal) -
FCA/Unesp, Botucatu.

ESPÍNDOLA, J.A.A.; GUERRA, J.G.; ALMEIDA, D.L. Adubação verde: estratégia para uma agricultura sustentável. Seropédica: Embrapa Agrobiologia, 1997. $20 p$.

GRAYER, R.J. et al. Infraspecific taxonomy and essential oil chemotypes in sweet basil, Ocimum basilicum. Phytochemistry, v.43, p.1033-9, 1996.

GONZÁLEZ, L.E. Efecto de La asociación de laurel ( $C$. alliodora (Ruiz Pav.) Oken) sobre producción de café (Coffea arabica) con y sin sombra de poro (Eritrina poeppigiana (Walpers) O.F. Cook). 1980. 110p. Dissertação (Mestrado) - Catie, Costa Rica.

KIEHL, E.J. Fertilizantes orgânicos. Piracicaba: Agronômica Ceres. 1985. 492p.

LOPES, A.S. Manual de fertilidade do solo. São Paulo: ANDA/POTAFOS. 11989. 53p.

MARTINS, E.R. Estudos em Ocimum selloi Benth: Isoenzimas, morfologia e óleo essencial. In: Plantas medicinais, aromáticas e condimentares: avanços na pesquisa agronômica. São Paulo: Ed. da UNESP, v.1, 1998. p.193-217.

MATOS, J.K.A. Plantas medicinais: aspectos agronômicos. Brasília: Universidade de Brasília. 1996. 51p.

MORHY, L. Metil-chavicol, cis e trans-anetol no óleo essencial de Ocimum selloi Benth. Anais da Academia Brasileira de Ciências, v.45, n.3-4, p.401-12, 1973.

MORAIS, L.A.S. et al. Composição química dos óleos essenciais de Ocimum selloi Benth. oriundo de populações espontâneas e cultivadas. SIMPÓSIO DE PLANTAS MEDICINAIS DO BRASIL. 17., 2002a. Anais ... Cuiabá - MT. 2002a.

MORAIS, L.A.S. et al. Influência da adubação sobre a produção de biomassa e no teor de óleo essencial do elixir paregórico. Horticultura Brasileira, v.20, p.363, supl. 2, 2002b. (CD-ROM).

PATON, A.; HARLEY, R.M.; HARLEY, M.M. Ocimum: an overview of classification and relationships. In: HOLM Y.; HILTUNEN, R. (Eds.). Ocimum: medicinal and aromatic plants - industrial profiles. Amsterdam: Ed. Hardman. 1999. p.1-38.

PRIMAVESI, O. Fatores limitantes da produtividade agrícola e plantio direto. São Paulo: BASF. 1982. 56p.

SANTOS, M.F. et al. Esterco bovino e biofertilizante no cultivo de erva-cidreira-verdadeira (Melissa officinallis L.). Revista Brasileira de Plantas Medicinais, v.11, p.355-9, 2009.

SCHMIDT, J.A. Labiatae. In: MARTIUS, K.F.P. (Ed). Flora Brasiliensis: Enumerato plantarum in Brasília. New York: Wheldon \& Wesley. 1858. p.117-338.

VANDERLINDE, F.A.; COSTA, E.A.; D'ANGELO, L.C.A. Atividades farmacológicas gerais e atividade antiespasmódica do extrato etanólico de Ocimum selloi Benth. In: SIMPÓSIO DE PLANTAS MEDICINAIS DO BRASIL, 13., 1994. Fortaleza. Anais... Fortaleza, UFCE. 1994. p.156.

VIEIRA, M.C. et al. Produção de biomassa de Mentha $x$ villosa Huds. e Mentha cf. Iongifolia Huds. em função da cama-de-aviário semi decomposta e de épocas de colheita. Revista Brasileira de Plantas Medicinais, v.4, p.25-9, 2002.

WINDHOLZ, M. The Merk index: an encyclopédia of chemical and drugs. 9.ed. Rahaway: Merk. 1v. 1976.

Rev. Bras. PI. Med., Botucatu, v.14, n.esp., p.246-249, 2012. 